\title{
НАЛОГОВОЕ РЕЗИДЕНТСТВО ФИЗИЧЕСКИХ И ЮРИДИЧЕСКИХ ЛИЦ: МЕЖДУНАРОДНЫЙ ОПЫТ И ПУТИ РАЗВИТИЯ КОНЦЕПЦИИ В РОССИИ
}

\begin{abstract}
Аннотация. Правила установления резидентства определяют широту распространения налоговой юрисдикции государства и налоговые условия деятельности для иностранных и внутренних инвесторов и компаний. В статье приведен аналитический обзор подходов зарубежных стран к определению резидентства физических и юридических лиц, рассмотрена концепция установления резидентства в контексте международной налоговой политики, сформулированы рекомендации для развития концепции резидентства в Российской Федерации. Исследованы взаимосвязи правил определения налогового резидентства, правил КИК, системы налогообложения доходов нерезидентов в контексте международной налоговой конкуренции. Авторы проводят сравнительный анализ лучшего зарубежного опыта, представленного в Комментариях к Модельной Конвенции об избежании двойного налогообложения ОЭСР, и российского налогового законодательства в части подходов к определению резидентства. Авторы приходят к нескольким важным выводам, среди которых вывод о том, что развитые страны склонны выбирать территориальную налоговую систему, а также, что в связи с движением на международном уровне к автоматическому обмену информацией между странами уклонение от статуса резидента России, где налоговые ставки находятся на достаточно низком уровне, становится выгодным только для физических лиц - потенциальных налоговых резидентов стран с еще более низким уровнем налогообложения физических лиц или отсутствием такового (например, Саудовская Аравия или отдельные офшорные юрисдикции), либо стран, в которых правила КИК отсутствуют. Ключевые слова: налоговое резидентство, налоговая политика, территориальная налоговая система, глобальная налоговая система, налоговая конкуренция, деофшоризация, КИК, СИДН, модельная конвенция ОЭСР, НДФЛ.
\end{abstract}

Abstract. The rules for defining the residency determines the scope of the tax jurisdiction of a state and fiscal conditions for foreign and domestic investors and companies. In their research the authors provide an analytical review of foreign states' approaches to defining the residency of individuals and legal entities and analyze the concept of residency in terms of international tax policy. The authors also make recommendations regarding development the residency concept in the Russian Federation. They study the connection between rules for defining the tax residency, CFC rules, and non-residents' income taxation system in terms of OECD double taxation avoidance, and Russian tax legislation in part of approaches to the definition of residency. The authors make several important conclusions, for example, that developed countries tend to choose the territorial taxation system. The other conclusion is that due to the international tendency towards automatic information exchange between countries, it is advantageous to avoid the status of Russia's residents even though tax rates are rather low in Russia for individuals who are potential residents of countries with lower individual tax rates or no tax rates at all (such as Saudi Arabia or particular offshore jurisdictions) or countries where CFC rules do not apply.

Keywords: deoffshorization, tax competition, global tax system, territorial tax system, tax policy, tax residency, CFC, DTT, OECD Model Convention, PIT.

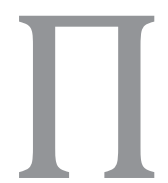

равила установления резидентства определяют широту распространения налоговой юрисдикции государства и налоговые условия деятельности для иностранных и внутренних инвесторов и компаний. В данной статье приведен аналитический обзор подходов зарубежных стран к определению резидентства физических и юридических лиц, рассмотрена концепция резидентства в контексте международной налоговой политики, сформулированы рекомендации для развития концепции резидентства в Российской Федерации. Авторы приходят к нескольким важным выводам, среди которых вывод о том, что развитые страны склонны выбирать территориальную налоговую систему, а также о том, что в связи с движением на международном уровне к автоматическому обмену информацией между странами уклонение от статуса резидента России, где налоговые ставки находятся на до- 


\section{Налоги и налогообложение 11(149) • 2016}

статочно низком уровне, становится выгодным только для физических лиц - потенциальных налоговых резидентов стран с еще более низким уровнем налогообложения физических лиц или отсутствием такового (например, Саудовская Аравия или отдельные офшорные юрисдикции), либо стран, в которых отсутствуют правила КИК. Статья представляет интерес для широкого круга лиц, как занимающихся научной деятельностью в области налогообложения, так и представителей бизнес-сообщества.

К настоящему времени в Российской Федерации произошел ряд законодательных нововведений в рамках политики деофшоризации. В частности, в 2015 году был выпущен закон о добровольном декларировании активов [1], в 2014 году были введены правила налогообложения контролируемых иностранных компаний, правило бенефециарного собственника (фактического право на доход), налоговое резидентство юридических лиц [2]; ранее были введены современные правила трансфертного ценообразования, в настоящее время в Государственной Думе Российской Федерации находится законопроект по реформированию правил налогообложения контролируемой задолженности («недостаточной капитализации») [3]. Данные законодательные новации проводятся в мировом тренде борьбы с уклонением корпораций от налогообложения, который выражается, например, в проекте BEPS ОЭСР/G20 [4].

Целью политики деофшоризации является помещение под налогообложение с помощью правил КИК прибыли, аккумулируемой в низконалоговых иностранных юрисдикциях, противодействие злоупотреблению СИДН через правило бенефициарного собственника, а также выявление иностранных компаний, контролируемых из России через правило налогового резидентства с последующим налогообложением их общемирового дохода. Некоторые комментаторы отмечают, что из-за того, что правило определения резидентства физических лиц не было изменено, многие бенефициары российских холдингов могут избежать российского налогообложения, просто сменив налоговое резидентство. В связи с этим перспективным направлением является проработка идеи о введении дополнительных критериев резидентства физических лиц, осно- ванных на критериях, используемых в зарубежной практике.

В данном отчете мы проводим аналитический обзор подходов зарубежных стран к определению резидентства физических и юридических лиц, рассматриваем концепцию резидентства в контексте международной налоговой политики, формулируем рекомендации для развития концепции резидентства в Российской Федерации.

Определение резидентства во внутреннем законодательстве

В первую очередь установление резидентства зависит от статуса лица - физическое или юридическое.

В первом случае многие страны определяют резидентство через взаимосвязь физического лица и государства. Законодательство таких стран предусматривает комбинацию объективных и субъективных критериев резидентства. Объективный критерий резидентства обычно предполагает нахождение в стране в течение установленного периода времени, например, лицо признается резидентом в налоговых целях, если оно пребывало в стране более 183 дней в течение 12-ти месяцев.

Этот тест является эффективным и объективным, если в стране действует соответствующий паспортный контроль на границе и его данные позволяют налоговым органам точно установить срок пребывания лица внутри страны. Это относительно легко обеспечивается в таких странах, как США и Япония, но малоприменимо в государствах одного политического блока, между которыми возможно свободное перемещение граждан, как, например, в Европейском Союзе.

Другие объективные критерии резидентства физического лица:

- визовый или миграционный статус физического лица, например, вид на жительство: имея вид на жительство, физическое лицо автоматически становится резидентом страны для налоговых целей;

- национальность: если физическое лицо имеет национальность страны пребывания, то оно автоматически приобретает статус ее налогового резидента;

- $\quad$ гражданство: приобретая гражданство страны, физическое лицо автоматически становится ее налоговым резидентом. Указанное 


\section{Международное налоговое право}

правило применяется, в частности, в США. Этот критерий также закреплен в исключающей оговорке Модельной конвенции об избежании двойного налогообложения США. Кроме того, бывший гражданин или резидент США будет обязан платить налоги в США еще на протяжении 10 лет после потери им указанного статуса [5].

Гражданство и национальность - это не одно и то же. Национальность - это юридический статус, отражающий отношение гражданина к стране и предполагающий его защиту со стороны государства. Национальность определяет, как врожденные, так и предоставляемые международным законодательством права физического лица, а гражданство обозначает комплекс прав, предоставляемых физическому лицу по местному законодательству. Таким образом, все граждане имеют национальность соответствующей страны, но физические лица, имеющие национальность страны, не обязательно являются ее гражданами [6].

Альтернативой является определение резидентства с помощью субъективного теста, выявляющего степень участия физического лица в социальной или экономической жизни государства. В одних странах этот тест используется как дополнение к закрепленному законодательно требованию нахождения в течение определенного периода, а в других странах он применяется в связи с отсутствием возможности достоверно определить срок нахождения физического лица в стране.

В ходе субъективного теста рассматриваются следующие обстоятельства:

- наличие постоянного местожительства или местопребывания на территории страны;

- наличие социальных и экономических интересов в стране, которое определяется путем исследования источников дохода физического лица, объектов инвестиций, участия в профессиональных объединениях, семейных связей, личных интересов и т.д.

Юридические лица

Тест на определение резидентства юридического лица также состоит из объективной и субъективной составляющих. Объективный фактор - место регистрации предприятия. Негативное последствие данного подхода в том, что компании могут формально регистрировать предприятия на нужной им территории.

Вследствие этого многие страны включают в тесты на резидентство субъективные факторы, например, осуществление экономической деятельности в стране. Резидентство компании определяется с помощью следующих вопросов.

1. Откуда осуществляется операционный менеджмент (ежедневное управление) компании? (такой подход применяется, например, в Дании)

2. Где размещается головной офис компании? (Бразилия, Словения и Япония)

3. Где проходят встречи Совета директоров?

4. Где размещаются центральные управленческие и контрольные органы компании? (Австралия, Канада, Кипр, Израиль и Великобритания)

5. Откуда происходит эффективное управление компанией? (Австрия, Бельгия, Китай, Греция, Хорватия, Италия, Нидерланды, Норвегия (эффективное управление не соотносится с исполнительным топ-менеджментом), Португалия, Южная Африка, Испания, Швейцария, Турция (эффективное управление определяется по месту нахождения топ-менеджмента))

6. Откуда осуществляется административное управления компанией? (Новая Зеландия)

7. Где осуществляется основная деятельность компании? (Франция)

8. Где реализуются ключевые бизнес-цели компании? (Италия)

9. Где реализуются голосующие права акционеров компании? (Гернси)

\section{Определение резидентства в Модельной конвенции ОЭСР}

Определение резидентства лица важно, как для внутреннего законодательства, так и для целей СИДН. Для стран, использующих концепцию резидентства, наличие у налогоплательщика указанного статуса обозначает, что налогом облагаются его общемировые доходы, и обычно налогоплательщик имеет доступ к таким налоговым льготам внутри страны, как налоговые вычеты или налоговые кредиты, основанные на семейном положении и персональном доходе, 


\section{Налоги и налогообложение 11(149) • 2016}

а также освобождение от двойного налогообложения доходов, полученных за рубежом. Для пользования положениями СИДН компания должна быть резидентом одного или обоих договаривающихся государств. Кроме того, понятие «предприятие договаривающегося государства» (часто использующееся в СИДН для установления обязанностей и прав) в статье $3(1)(d)$ модели СИДН, предлагаемой ОЭСР, увязывается с понятием резидентства. Статья $3(1)(d)$ определяет «предприятие договаривающего государства» как предприятие, управляемое резидентом соответствующего государства.

Итак, что понимается под резидентом договаривающегося государства для получения льгот по СИДН? Ответ может быть найден в определении, приведенном в статье 4(1) МК ОЭСР:

«Под резидентом договаривающегося государства понимается лицо, которое в соответствии с законами данного государства, подлежит налогообложению в нем исходя из его местожительства, резидентства, управления или иного аналогичного критерия... В то же время данный термин не включает лиц, которые подлежат налогообложению в договаривающемся государстве только по причине получения дохода или размещения капитала в нем.»

Данное определение заставляет нас вновь обратиться ко внутреннему законодательству, чтобы уточнить, когда лицо признается резидентом государства по признаку месту жительства, проживания, места управления или другого аналогичного критерия. В действительности многие государства используют по крайней мере один из вышеназванных признаков. Таким образом, наблюдается перенос критериев резидентства из внутреннего законодательства в СИдН.

Определение включает два ограничения для признания резидентства в целях СИДН. Во-первых, определение требует, чтобы лицо «в соответствии сзаконами государства подлежало налогообложению в нем по причине местожительства, проживания, места управления или другого аналогичного критерия». Таким образом, резидентом для целей ДидН не могут являться организации, освобожденные в соответствии с внутренними законами от уплаты налогов (например, благотворительные).
Вторым ограничением является то, что понятие «резидент страны»не обозначает «физическое лицо, подлежащее налогообложению в связи исключительно с получением дохода в этой стране или размещении в ней капитала». Другими словами, получение дохода в стране, владение капиталом в ней и уплата налогов не делает физическое лицо резидентом данной страны. Для того, чтобы быть резидентом, необходимо соответствовать критериям, определенным в первом положении статьи 4(1).

\section{Случаи двойного резидентства}

Применяя внутренние критерии резидентства, две страны могут заявить о своих правах на налогообложение одного и того же лица (физическое или юридическое), признав его своим резидентом. Такой конфликт приводит к двойному налогообложению, а налогоплательщик именуется двойным резидентом.

В отсутствие СИДН такой налогоплательщик будет вынужден платить дважды налог с одного и того же дохода. Для предотвращения таких ситуаций СИДН должны содержать критерии признания лица резидентом только одного из договаривающихся государства. Такие правила могут быть найдены в статье 4(2) (для физических лиц) и статье 4(3) (для юридических) лиц модельного соглашения ОЭСР.

\section{Физические лица}

В статье 4(2) МК ОЭСР приведена иерархия критериев признания физического лица резидентом того или иного государства. Когда физическое лицо признано резидентом обоих договаривающихся государств, его статус может быть определен следующим образом:

- лицо признается налоговым резидентом государства его постоянного места жительства; при наличии постоянных мест проживания в обоих государствах критерием признания налогового резидентства являются более тесные экономические и личные связи с одним из государств (центр жизненных интересов);

- $\quad$ если постоянное местожительства не имеется ни в одном из государств, а определение центра жизненных интересов является затруднительным, то лицо признается рези- 


\section{Международное налоговое право}

дентом государства его наиболее частого местопребывания;

- если лицо не имеет местопребывания ни одном из государств или его определение затруднено, то критерием признания его резидентом становится национальная принадлежность;

- $\quad$ если лицо является одновременно представителем национальности обоих договаривающихся государств, то его резидентство определяется на основе договоренности между указанными государствами.

Итак, первый признак - местонахождение лица. Для целей СИДН физическое лицо признается резидентом страны, в которой находится его постоянное местожительства. Если такое место есть в обоих государствах, то следует определить, где располагаются его жизненные интересы. Это производится с помощью оценки фактов и обстоятельств. Если центр жизненных интересов не может быть установлен однозначно, то применяется критерий наиболее частого местопребывания. Если это место в обоих государствах или ни в одном из них, то следует посмотреть на национальность. На этом этапе резидентство обычно удается установить. В противном случае, если лицо имеет национальность обоих государств или ни одного из них, то резидентство устанавливается путем договоренности между компетентными органами государств.

\section{Юридические лица}

Правило эффективного управления для компании, являющейся резидентом двух стран, определяет ее резидентом той страны, которая является местом эффективного управления ею (ст. 4(3) МК ОЭСР). Несмотря на важность понятия «место эффективного управления», в статье оно не определяется. Однако комментарии ОЭСР показывают, что определение места управления опирается на анализ фактов. В комментарии к статье 4(3) место эффективного управления интерпретируется как «место, в котором принимаются ключевые управленческие и коммерческие решения, необходимые для обеспечения деятельности компании». Место эффективного управления находится там, где ключевой управленческий персонал (например, совет директоров) в действительности принимает решения, которые определяют действия компании.
Однако никакого конкретного определения месту эффективного управления нет и для его определения должен быть произведен анализ фактов и обстоятельств.

Ключевыми в данном комментарии являются слова - ключевые управленческие и коммерческие решения, по существу необходимые для ведения бизнеса, в действительности принимаются. Уровень принятия таких решений (совет директоров или высший менеджмент) зависит от конкретных обстоятельств.

\section{Актуальные проблемы определения резидентства в России}

В Российской Федерации в отношении физических лиц действует «правило 183 дней», в соответствии с которым если лицо находится в России 183 или более дней в течение года, то оно считается налоговым резидентом (п. 2 ст. 207 НК РФ). Заметим, что недавно ФНС России был выпущен ряд писем [7;8], в которых развивалось мнение о том, что в заключенных Российской Федерацией СИДН, основанных на МК ОЭСР, содержатся специальные правила определения резидентства физических лиц, отличные от действующих в России, в частности правило признания лица резидентом по месту нахождения центра жизненных интересов. Данное толкование представляется противоречащим действующему законодательству, о чем было указано в письме Минфина от 21.04.2016 №03-08Р3/23009. Отметим, что оно не имеет основания ни в налоговом праве, ни в профессиональной академической литературе, поскольку, как было указано выше, МК ОЭСР и основанные на ней СИДН, заключенные Россией, не устанавливают специальных правил определения резидентства, а только позволяют предотвратить конфликт в случае признания лица резидентом нескольких стран одновременно.

В отношении юридических лиц действует основное правило определения резидентства юридического лица по месту его управления (ст. 246.2 НК РФ). При этом местом управления считается Российская Федерация при соблюдении хотя бы одного из следующих условий:

- исполнительный орган (исполнительные органы) организации регулярно осущест- 


\section{Налоги и налогообложение 11(149) • 2016}

вляет свою деятельность в отношении этой организации из Российской Федерации;

- $\quad$ главные (руководящие) должностные лица организации (лица, уполномоченные планировать и контролировать деятельность, управлять деятельностью предприятия и несущие за это ответственность) преимущественно осуществляют руководящее управление этой иностранной организацией в Российской Федерации.

В случае конфликта с другой страной вида резидентство-резидентство и при соблюдении в этой другой стране хотя бы одного из указанных выше условий следует применять дополнительные критерии. Так, лицо будет считаться резидентом Российской Федерации, если выполняется хотя бы одно из них:

- ведение бухгалтерского или управленческого учета организации (за исключением действий по подготовке и составлению консолидированной финансовой и управленческой отчетности, а также анализу деятельности иностранной организации) осуществляется в Российской Федерации;

- ведение делопроизводства организации осуществляется в Российской Федерации;

- $\quad$ оперативное управление персоналом организации осуществляется в Российской Федерации.

Кроме того, Россия является участницей 80 СИДН, в которых имеются положения, основанные на соответствующих статьях Модельной конвенции ОЭСР об избежании двойного налогообложения, определяющие правила определения налогового резидентства для целей применения соглашений (отсылающие к национальному законодательству), а также правила при конфликте вида резидентство-резидентство.

Как отмечают эксперты [9] в настоящее время для того, чтобы иностранная компания, входящая в холдинг, получающий свою основную прибыль от деятельности в России, смогла максимально снизить вероятность быть признанной налоговым резидентом России, ей целесообразно организовать свою деятельность так, чтобы:

1) руководящее управление иностранным элементом было выведено за пределы РФ и этот факт был подтвержден документально;
2) было создано серьезное управляющее присутствие за границей, например, полноценный управленческий офис за рубежом, в котором бы регулярно принимались решения, что значительно снижает риск признания иностранных компаний группы налоговыми резидентами РФ. При этом управляющую компанию необходимо расположить в государстве, в котором отсутствует законодательство по признанию иностранных юридических лиц налоговыми резидентами по месту управления (к примеру, Латвия, Эстония, ОАЭ, Бахрейн, либо где такая деятельность не облагается налогом - например, Джерси, Гернси).

Значение концепции налогового резидентства при формировании международной налоговой политики

Ненадежность концепции резидентства в условиях глобализации

Существующие международные налоговые правила опираются на концепции «резидентства» и «источника дохода», которые глобализация сделала очень уязвимыми (если не сказать бессмысленными). Разделение прав на взимание налогов между страной резидентства и страной - источником дохода долгое время вызывало споры, а недавно стало центром внимания в академической среде. Традиционные налоговые правила ведут к несправедливому распределению налоговой базы, что может существенно подорвать согласованность международной налоговой системы. Технологическая революция изменила привычные способы ведения бизнеса. Теперь для совместного ведения бизнеса нет необходимости физического присутствия. Этот факт может оказать существенное влияние на определение резидентства компаний и мест эффективного управления ими. В условиях глобализации управление компанией может одновременно осуществляться из нескольких стран. Компания может иметь офис, но управление будет осуществляться посредством электронных средств коммуникации. Возможными становятся виртуальные встречи Совета директоров и акционеров компании.

В такой ситуации место эффективного управления может отсутствовать. Место эффективного управления может быть определено исходя из места нахождения менеджера в момент 


\section{Международное налоговое право}

принятия управленческого решения, однако установление такого места видится затруднительными, если не сказать невозможным. Как, к примеру, установить место, если половина членов совета директоров находится в стране А, другая половина в стране В, а их общение происходит посредством видеосвязи? Или, например, встречи совета директоров происходят в разных местах в течение одного года.

Более того, возможна ситуация, когда глава управленческого персонала компании находится в постоянных разъездах, перемещаясь между офисами и заводами компании. В таких случаях место эффективного управления является мобильным. Кроме того, компания, которая признается резидентом двух государств одновременно, может управляться из третьей страны. Несмотря на подобные варианты, ОЭСР в своем комментарии указывает, что «управление предприятием может осуществляться из нескольких мест, однако место эффективного управления будет одно».

Проникновение информационно-коммуникационных технологий в экономику вызывает проблемы, для решения которых прежние правила налогообложения не были предназначены (ОЭСР (2014)). Теперь резидентство не является постоянным атрибутом компании и может быть искусственно изменено. Кроме того, все чаще встречаются ситуации, когда страна резидентства компании и ее бенефициаров не совпадают. Подобные вопросы находятся в фокусе внимание в Плане BEPS 0ЭСP/G20.

Уклонение от сбора при репатриации капитала или правил налогообложения контролируемых иностранных компаний (КИК) путем изменения страны резидентства компании называют налоговой инверсией (tax inversion). В период с 1997 по 2007 годы около 6\% МНК в мире поменяли месторасположения своих головных офисов. Исследование Вогет (2011) [10] показало, что повышение налоговой ставки на 10 процентов увеличивает вероятность таких перемещений более чем на одну треть. Исследование, проведенное Хейзинга и Вогет (2009), показало, что если США откажется от глобальной системы налогообложения, то количество компаний, выбирающих эту страну для размещения своих головных офисов, увеличится на 5 процентов.

\section{Выводы}

Понятие резидентства тесно связано с другими элементами системы налогообложения, определяющими налоговую политику, такими, как выбор системы налогообложения резидентов (глобальная или территориальная), наличие правил КИК, наличие СИДН с другими странами, налоговая ставка. В совокупности данные правила определяют, насколько широко распространяется налоговая юрисдикция государства и каковы в результате налоговые условия для иностранных и внутренних инвесторов и компаний. Россия - страна с глобальной системой налогообложения, а также правилами КИК. В контексте международной налоговой политики анализ зарубежного опыта приводит нас к следующим выводам.

1. Более развитые страны (почти все страны, кроме США и Южной Кореи, которые помимо G20 входят и в ОЭСР) выбирают территориальную налоговую систему, которая является более нейтральной и справедливой. Это связано с тем, что на территории данных стран создается большое количество добавленной стоимости по причине их высокого уровня развития, кроме того, данные страны активно конкурируют за международные инвестиции и используют для выигрыша все доступные средства. Таким образом, основная предпосылка выбора данными странами территориальной системы налогообложения - это то, что они больше заработают за счет привлечения новых иностранных инвестиций (новых компаний-резидентов), чем потеряют от неналогообложения иностранных доходов своих существующих резидентов. Кроме того, территориальная налоговая система более проста в администрировании. Отметим также, что данные страны в основном используют похожие на российские критерии определения резидентства физических и юридических лиц по причине их объективности.

2. Российская Федерация на данном этапе социально-экономического развития находится, скорее, в категории стран с переходной экономикой, поэтому она конкурирует за международные инвестиции в первую очередь со странами с аналогичным уровнем социально-экономического развития (это прежде всего страны БРИКС). 


\section{Налоги и налогообложение 11(149) • 2016}

Как видно из данных Приложения 1, во всех странах БРИКС действуют глобальные системы налогообложения, что отвечает их интересам по налогообложению действующих резидентов. Для данных стран, богатых природными ресурсами, с точки зрения международной налоговой политики наиболее актуальной проблемой является, во-первых, налогообложение входящих инвестиций (поскольку это страны - импортеры капитала), т.е. увеличение прав страныисточника; во-вторых, создания максимально эффективных инструментов для борьбы с размыванием налоговой базы и выводом прибыли в низконалоговые юрисдикции как со стороны иностранных, так и внутренних инвесторов, а также защита национальной налоговой базы; втретьих, поддержание налоговых ставок на более выгодном уровне, чем у стран - прямых конкурентов; в-четвертых, обеспечение стабильности налоговых правил; в-пятых, совершенствование налогового администрирования. Российская Федерация достаточно успешно развивает свою систему налогообложения с учетом указанных выше приоритетов. Так, в Российской Федерации недавно были введены правила КИК (что позволило восстановить принцип нейтральности экспорта капитала) [14], действует глобальная система налогообложения резидентов, ориентированная прежде всего на то, чтобы распространить юрисдикцию на доходы от деятельности в России, искусственно помещаемые на различные иностранные компании. Действуют более привлекательные, чем у конкурентов по странам БРИКС, налоговые ставки.

3. Введенные в Российской Федерации в рамках деофшоризационного пакета правила определения налогового резидентства юридических лиц являются крайне важным и правильным шагом в развитии налогового права России, правильным и важным действием в рамках налоговой политики, поскольку отвечают указанным выше приоритетам, при этом, однако, их введение несет в себе определенные риски. Во-первых, это риск ухудшения инвестиционного климата в России по причине неясности в отношении развития практики применения данных правил. Это связано с тем, что множество примеров свидетельствуют о том, что интерпретация налогового законодательства налоговыми органами и судами часто имеет место не в соответствии с духом и буквой закона, а в соответствии с интересами бюджета (см., например, вышеупомянутое Письмо ФНС России от 16 января 2015 г. N 0A-3-17/87@; от 29.01.2016 г. №0A-4-17/1265@; ряд нашумевших судебных дел, например, дело «Орифлейм Косметикс»и др.). Во-вторых, это общий риск для всех стран, связанный с глубоким кризисом концепции налогового резидентства в частности и правил международного налогообложения в целом в условиях современной глобализированной экономики, основанной на информационно-коммуникационных технологиях.

4. Действующие в Российской Федерации правила определения налогового резидентства физических лиц основаны на объективном критерии физического присутствия данных лиц в России. Это обеспечивает простоту в администрировании данного правила и определенность в отношении практики его применения. При этом ряд стран использует также некоторые субъективные критерии для определения налогового резидентства. Наиболее перспективными из них для имплементации в России нам представляются наличие социальных и экономических интересов в стране, которое определяется путем исследования источников дохода физического лица, объектов инвестиций, участия в профессиональных объединениях, семейных связей, личных интересов и т.д. (такие критерии используются, например, в Мексике, во Франции, в Китае). Использование данных критериев может позволить противодействовать искусственному изменению налогового резидентства российскими бенефициарами с целью уклонения от обязанностей по предоставлению отчетности по КИК и уплаты налогов с прибыли КИК. При этом существует риск в виде усложнения администрирования данного правила, увеличения конфликтов с другими юрисдикциями, в которых лицо также может считаться налоговым резидентом, а также ухудшением инвестиционного климата по причине нестабильности налоговых правил.

5. В связи с движением на международном уровне к автоматическому обмену информацией между странами уклонение от статуса резидента России, где налоговые ставки находятся на достаточно низких уровнях, становится выгодным 


\section{Международное налоговое право}

только для физических лиц - потенциальных налоговых резидентов стран с еще более низким уровнем налогообложения физических лиц или отсутствием такового, таких, как Саудовская Аравия или отдельные офшорные юрисдикции, либо стран, в которых правила КИК отсутствуют (отметим, что такие правила, а следовательно, обязанность по декларированию своих зарубежных активов имеется почти во всех странах G20). В этой связи на данном этапе представляется целесообразным не изменять критерии при- знания налоговым резидентом для российских физических лиц до тех пор, пока не сложится практика автоматического обмена информацией между странами и применения правил КИК и прочих элементов деофшоризационного пакета законодательства, поскольку ужесточение этих правил может стать избыточной мерой, в которой отсутствует необходимость. Такое изменение должно основываться на ясной цели международной налоговой политики, а не на краткосрочных фискальных интересах.

\section{Библиография}

1. Федеральный закон Российской Федерации от 8 июня 2015 г. №140-ФЗ «0 добровольном декларировании физическими лицами активов и счетов (вкладов) в банках и о внесении изменений в отдельные законодательные акты Российской Федерации». 29 с.

2. Федеральный закон Российской Федерации от 24 ноября 2014 года №376-Ф3 «0 внесении изменений в части первую и вторую налогового кодекса Российской Федерации (в части налогообложения прибыли контролируемых иностранных компаний и доходов иностранных организаций)». $24 \mathrm{c}$.

3. Проект федерального закона «О внесении изменений в статью 269 части второй Налогового кодекса Российской Федерации в части определения понятия контролируемой задолженности». Вносят депутаты Государственной Думы Г.Я. Хор, А.М. Макаров

4. Котляров М.А., Рыкова И.Н. Противодействие переносу налоговой базы в низконалоговые юрисдикции: опыт ОЭСР и приоритеты для России. Научно-исследовательский финансовый институт. Финансовый журнал. №4 (22), 2014. C. 47-54.

5. Article 1 (4) of the United States model income tax convention of November 15, 2006 convention between the government of the United States of America and the government of ------- for the avoidance of double taxation and the prevention of fiscal evasion with respect to taxes on income. 43 p. URL: https://www. irs.gov/pub/irs-trty/model006.pdf

6. State Trading Corporation v. Commercial Tax Officer (1963) 2 SCJ 605 (India). 61 p.

7. Письмо ФНС России от 16.01.2015 г. №OA-3-17/87@

8. Письмо ФНС России от 29.01.2016 г. №0A-4-17/1265@

9. Гидирим В.А. Принцип резидентства корпораций в международном налоговом праве. Налоги и налогообложение. №2, 2013. С. 123-170

10. Voget, Johannes. Headquarter Relocations and International Taxation. Journal of Public, Economics, Vol. 95 (October), 2011. Pp. 1067-81

11. Diamond, Peter, and James A. Mirrlees. Optimal Taxation and Public Production I: Production Efficiency. American Economic Review, Vol. 61 (March), 1971. Pp. 8-27

12. Musgrave, Peggy B. United States Taxation of Foreign Investment Income: Issues and Arguments. International Tax Program (Cambridge, Massachusetts: Law School of Harvard University), 1969. 564 p.

13. Статья 26 (внутренний рынок), 49 to 55 (установление) and 56 to 62 (услуги) Договора о функционировании Европейского Союза (Treaty on the Functioning of the European Union (TFEU)). 326 p. URL: http://www.europarl.europa.eu/atyourservice/en/displayFtu.html?ftuId=FTU_3.1.4.html

14. Милоголов Н.С., Пинская М.Р. Правила налогообложения контролируемых иностранных компаний: сравнительный анализ. Научно-исследовательский финансовый институт. Финансовый журнал. №4 (22), 2014. С. 36-46 


\section{Налоги и налогообложение 11(149) • 2016}

15. T. Matheson, V. Perry, Ch. Veung WP/13/205 IMF Working Paper Fiscal Affairs Department Territorial vs. Worldwide Corporate Taxation: Implications for Developing Countries. October, 2013. 25 p.

16. Philip Dittmer. A Global Perspective on Territorial Taxation. Tax foundation. August 10, 2012. 28 p.

17. OECD Model Tax Convention on Income and on Capital CONDENSED VERSION. July 2010. 466 p.

18. K. Holmes International Tax Policy and Double Tax Treaties. Second Revised Edition. IBFD. 2014; OECD Model Convention on Income and Capital. Condensed Version of July 2010. 432 p.

19. T. J. Atwood, G. Ryan Huston, Dana Wallace. Are worldwide tax systems disadvantageous for resident firms compared with territorial tax systems? May, 2013. 43 p.

20. OECD (2014), Action Plan on Base Erosion and Profit Shifting (Russian version), OECD Publishing. 56 p. http://dx.doi.org/10.1787/9789264207837-ru

21. Imf policy paper. Spillovers in international corporate taxation. May 9, 2014. 86 p. URL: https://www. imf.org/external/np/pp/eng/2014/050914.pdf

22. OECD (2015), Addressing the Tax Challenges of the Digital Economy, Action 1-2015 Final Report, OECD/G20 Base Erosion and Profit Shifting Project, OECD Publishing, Paris. 288 p. http://dx.doi. org/10.1787/9789264241046-en

\section{References (transliterated)}

1. Federal'nyi zakon Rossiiskoi Federatsii ot 8 iyunya 2015 g. №140-FZ «0 dobrovol'nom deklarirovanii fizicheskimi litsami aktivov i schetov (vkladov) v bankakh i o vnesenii izmenenii v otdel'nye zakonodatel'nye akty Rossiiskoi Federatsii». 29 c.

2. Federal'nyi zakon Rossiiskoi Federatsii ot 24 noyabrya 2014 goda №376-FZ «0 vnesenii izmenenii v chasti pervuyu i vtoruyu nalogovogo kodeksa Rossiiskoi Federatsii (v chasti nalogooblozheniya pribyli kontroliruemykh inostrannykh kompanii i dokhodov inostrannykh organizatsii)». $24 \mathrm{c}$.

3. Proekt federal'nogo zakona «O vnesenii izmenenii v stat'yu 269 chasti vtoroi Nalogovogo kodeksa Rossiiskoi Federatsii v chasti opredeleniya ponyatiya kontrolir uemoi zadolzhennosti». Vnosyat deputaty Gosudarstvennoi Dumy G.Ya. Khor, A.M. Makarov

4. Kotlyarov M.A., Rykova I.N. Protivodeistvie perenosu nalogovoi bazy v nizkonalogovye yurisdiktsii: opyt OESR i prioritety dlya Rossii. Nauchno-issledovatel'skii finansovyi institut. Finansovyi zhurnal. №4 (22), 2014. S. 47-54.

5. Article 1 (4) of the United States model income tax convention of November 15, 2006 convention between the government of the United States of America and the government of ------- for the avoidance of double taxation and the prevention of fiscal evasion with respect to taxes on income. 43 p. URL: https://www. irs.gov/pub/irs-trty/model006.pdf

6. State Trading Corporation v. Commercial Tax Officer (1963) 2 SCJ 605 (India). 61 p.

7. Pis'mo FNS Rossii ot 16.01.2015 g. №OA-3-17/87@

8. Pis'mo FNS Rossii ot 29.01.2016 g. №OA-4-17/1265@

9. Gidirim V.A. Printsip rezidentstva korporatsii v mezhdunarodnom nalogovom prave. Nalogi i nalogooblozhenie. №2, 2013. C. 123-170

10. Voget, Johannes. Headquarter Relocations and International Taxation. Journal of Public, Economics, Vol. 95 (October), 2011. Pp. 1067-81

11. Diamond, Peter, and James A. Mirrlees. Optimal Taxation and Public Production I: Production Efficiency. American Economic Review, Vol. 61 (March), 1971. Pp. 8-27

12. Musgrave, Peggy B. United States Taxation of Foreign Investment Income: Issues and Arguments. International Tax Program (Cambridge, Massachusetts: Law School of Harvard University), 1969. 564 p.

13. Stat'ya 26 (vnutrennii rynok), 49 to 55 (ustanovlenie) and 56 to 62 (uslugi) Dogovora o funktsionirovanii Evropeiskogo Soyuza (Treaty on the Functioning of the European Union (TFEU)). 326 p. URL: http://www. europarl.europa.eu/atyourservice/en/displayFtu.html?ftuId=FTU_3.1.4.html 
14. Milogolov N.S., Pinskaya M.R. Pravila nalogooblozheniya kontroliruemykh inostrannykh kompanii: sravnitel'nyi analiz. Nauchno-issledovatel'skii finansovyi institut. Finansovyi zhurnal. №4 (22), 2014. S. 36-46

15. T. Matheson, V. Perry, Ch. Veung WP/13/205 IMF Working Paper Fiscal Affairs Department Territorial vs. Worldwide Corporate Taxation: Implications for Developing Countries. October, 2013. 25 p.

16. Philip Dittmer. A Global Perspective on Territorial Taxation. Tax foundation. August 10, 2012. 28 p.

17. OECD Model Tax Convention on Income and on Capital CONDENSED VERSION. July 2010. 466 p.

18. K. Holmes International Tax Policy and Double Tax Treaties. Second Revised Edition. IBFD. 2014; OECD Model Convention on Income and Capital. Condensed Version of July 2010. 432 p.

19. T. J. Atwood, G. Ryan Huston, Dana Wallace. Are worldwide tax systems disadvantageous for resident firms compared with territorial tax systems? May, 2013. 43 p.

20. OECD (2014), Action Plan on Base Erosion and Profit Shifting (Russian version), OECD Publishing. 56 p. http://dx.doi.org/10.1787/9789264207837-ru

21. Imf policy paper. Spillovers in international corporate taxation. May 9, 2014. 86 p. URL: https://www. imf.org/external/np/pp/eng/2014/050914.pdf

22. OECD (2015), Addressing the Tax Challenges of the Digital Economy, Action 1-2015 Final Report, OECD/G20 Base Erosion and Profit Shifting Project, OECD Publishing, Paris. 288 p. http://dx.doi. org/10.1787/9789264241046-en 